\title{
Focus on renal blood flow in mechanically ventilated patients with SARS-CoV-2: a prospective pilot study
}

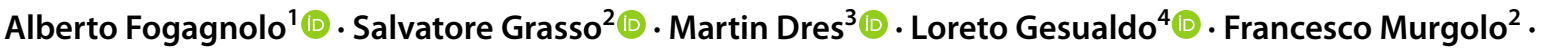

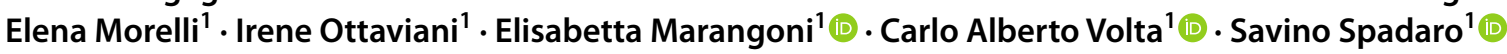

Received: 29 July 2020 / Accepted: 9 December 2020 / Published online: 1 January 2021

(c) The Author(s), under exclusive licence to Springer Nature B.V. part of Springer Nature 2021

\begin{abstract}
Mechanically ventilated patients with ARDS due to the severe acute respiratory syndrome coronavirus-2 (SARS-CoV-2) seem particularly susceptible to AKI. Our hypothesis was that the renal blood flow could be more compromised in SARSCoV-2 patients than in patients with "classical" ARDS. We compared the renal resistivity index (RRI) and the renal venous flow (RVF) in ARDS patients with SARS-CoV-2 and in ARDS patients due to other etiologies. Prospective, observational pilot study performed on 30 mechanically ventilated patients (15 with SARS-COV-2 ARDS and 15 with ARDS). Mechanical ventilation settings included constant-flow controlled ventilation, a tidal volume of $6 \mathrm{ml} / \mathrm{kg}$ of ideal body weight and the PEEP level titrated to the lowest driving pressure. Ultrasound Doppler measurements of RRI and RVF pattern were performed in each patient. Patients with SARS-COV-2 ARDS had higher RRI than patients with ARDS (0.71[0.67-0.78] vs 0.64[0.60-0.74], $p=0.04)$. RVF was not-continuous in 9/15 patients $(71 \%)$ in the SARS-COV-2 ARDS group and in and 5/15 (33\%) in the ARDS group $(p=0.27)$. A linear correlation was found between PEEP and RRI in patients with SARS-COV-2 ARDS $\left(\mathrm{r}^{2}=0.31 ; p=0.03\right)$ but not in patients with ARDS. Occurrence of AKI was $53 \%$ in patients with SARS-COV-2 ARDS and 33\% in patients with ARDS $(p=0.46)$. We found a more pronounced impairment in renal blood flow in mechanically ventilated patients with SARS-COV-2 ARDS, compared with patients with "classical" ARDS.
\end{abstract}

Keywords ARDS · COVID-19 · SARS-CoV-2 $\cdot$ Coronavirus · Mechanical ventilation · Renal resistivity index · Acute kidney injury

$\begin{array}{ll}\text { Abbreviations } \\ \text { ARDS } & \begin{array}{l}\text { Acute respiratory distress syndrome } \\ \text { KDIGO }\end{array} \\ & \begin{array}{l}\text { Kidney Disease: Improving Global } \\ \text { Outcomes }\end{array} \\ \text { MV } & \text { Mechanical ventilation } \\ \text { ROC } & \text { Receiver operator characteristic } \\ \text { RRI } & \text { Renal resistivity index } \\ \text { RRT } & \text { Renal replacement therapy } \\ \text { RVF } & \text { Renal venous flow pattern }\end{array}$

SARS-CoV-2 Acute respiratory syndrome coronavirus 2

\section{Introduction}

The occurrence of acute kidney injury (AKI) in mechanically ventilated patients with acute respiratory distress syndrome (ARDS) due to the novel severe acute respiratory syndrome coronavirus 2 (SARS-CoV-2) ranges between 15 and $23 \%$ being as high as $50 \%$ in non-survivors. [1,

$4 \quad$ Nephrology Dialysis and Transplantation Unit, Department of Emergency and Organ Transplantation, Università degli Studi di Bari "Aldo Moro", Bari, Italy 
2]. COVID-19 may per se induce a kidney disease [3] but mechanical ventilation (MV) could play a pivotal role.

Recent guidelines recommend the use of lung-protective mechanical ventilation in ARDS, consisting in low tidal volume (VT) and relatively high positive end-expiratory pressure (PEEP) [4]. This strategy could have a relevant hemodynamic impact [5, 6] and has been shown to increase renal arterial resistances and decrease renal venous return, leading to glomerular congestion and increase in kidney interstitial hydrostatic pressures [5-8]. In SARS-COV-2 ARDS respiratory system compliance $\left(\mathrm{C}_{\mathrm{RS}}\right)$ could be atypically high compared to the degree of arterial hypoxemia, leading the application of relatively high PEEP levels $[9,10]$. Since the hemodynamic impact of PEEP is inversely proportional to respiratory system compliance $\left(\mathrm{C}_{\mathrm{RS}}\right)$, it might be then hypothesized that PEEP in patients with COVID-19 infection could result in greater extent of kidney damage compared to ARDS due to different etiologies.

Our hypothesis was that the degree of renal blood flow impairment in SARS-COV-2 ARDS compared to "classic" ARDS could be more pronounced. Accordingly, we performed an ultrasound evaluation of the renal resistivity index (RRI) and renal venous flow pattern (RVF) [11-13] in two groups of patients, i.e. with SARS-COV-2 ARDS and with classical ARDS, ventilated with the same lung-protective protocol.

\section{Materials and Methods}

\subsection{Population}

Prospective, observational pilot study performed in a COVID-19 Intensive Care Unit (ICU) and a mixed medical-surgical ICU at University Hospital of Ferrara, Italy. The study was approved by the ethic committee (approval number 339/2020). We included consecutive patients with SARS-COV-2 ARDS or ARDS undergoing mechanical ventilation. Exclusion criteria were: diagnosis of AKI before ICU admission, unsatisfactory ultrasound visualization, arrhythmia, renal replacement therapy and denied consent. All patients included in the SARS-COV-2 ARDS group had laboratory-confirmed COVID-19.

\subsection{Mechanical ventilation settings}

At the time of renal blood flow assessment, all patients were deeply sedated and paralyzed with continuous infusion of cis-atracurium $1-3 \mathrm{mcg} / \mathrm{kg} / \mathrm{min}$ for clinical reasons. Mechanical ventilation settings included constantflow controlled ventilation, a tidal volume of $6 \mathrm{ml} / \mathrm{kg}$ of ideal body weight and the PEEP level titrated to the lowest driving pressure. [14, 15] Briefly, PEEP was increased by $2 \mathrm{~cm} \mathrm{H}_{2} \mathrm{O}$ step starting from $6 \mathrm{~cm} \mathrm{H}_{2} \mathrm{O}$, up to the PEEP level leading to a static end-inspiratory plateau pressure ( $\mathrm{P}_{\mathrm{PLAT}}$ ) of $28-30 \mathrm{~cm} \mathrm{H}_{2} \mathrm{O}$; then, the PEEP level corresponding to the lowest driving pressure was chosen.

The driving pressure was measured as:

$\mathrm{P}_{\text {PLAT }}-$ PEEP $_{\text {TOT }}$.

where $\mathrm{PEEP}_{\mathrm{TOT}}$ is the total static positive end-expiratory pressure. $\mathrm{P}_{\mathrm{PLAT} \text { and }}$ PEEP $_{\text {TOT }}$ were measured through the occlusion technique (i.e. a $4 \mathrm{~s}$ airway opening occlusion maneuver at end-inspiration and end-expiration, respectively) [16].

\subsection{Renal blood flow assessment}

Ultrasound evaluation of renal blood flow was performed within $24 \mathrm{~h}$ from starting of MV. All the measurements were taken by a single well-trained anesthesiologist with certified experience (FA) on the right kidney with the patient in semirecumbent position $\left(30^{\circ}\right)$, through a posterolateral approach. Color Doppler images were used to identify the interlobar vessels. An interlobar or arcuate artery was selected for pulse wave Doppler measurements and RRI was calculated as:

peak systolic velocity - end diastolic velocity/peak systolic velocity.

A representative Renal Resistivity Index measurement technique performed is showed in Fig. 1.

An RRI $>0.7$ was deemed pathological. [11-13]

The RVF pattern was classified as continuous, biphasic or monophasic [11]. Under physiological conditions, the RVF pattern is continuous, whereas during renal congestion it becomes biphasic or even monophasic [11].

For both RRI and RVF three measurements were obtained over 3 cardiac cycles and the mean value was recorded for analysis.

\subsection{Secondary outcomes}

The occurrence of AKI, as well as need for renal replacement therapy (RRT), was recorded. Further, we investigated the ability of RRI to predict the occurrence of AKI and the need of RRT. AKI was defined according to the Kidney Disease: Improving Global Outcomes (KDIGO) guidelines as an increase in serum creatinine of $0.3 \mathrm{mg} / \mathrm{dL}$ within $48 \mathrm{~h}$, an increase in serum creatinine to 1.5 times the baseline value present within the previous 7 days, or a urinary output $<0.5 \mathrm{~mL} / \mathrm{kg} / \mathrm{h}$ for $6 \mathrm{~h}$ [17]. Indications for RRT were serum urea $>150 \mathrm{mg} / \mathrm{dL}$, severe hyperkalemia (over $6 \mathrm{mmol} / \mathrm{L}$ or with sign of electrocardiogram 




Fig. 1 A representative Renal Resistivity Index measurement technique performed in patients with SARS-CoV-2 ARDS at PEEP $10 \mathrm{~cm}$ $\mathrm{H}_{2} \mathrm{O}$

abnormalities), urine output $<200 \mathrm{~mL} / \mathrm{die}$, fluid overload despite diuretic treatment [18].

\subsection{Statistical analysis}

Categorical data are presented as frequencies and percentages, while continuous variables as mean \pm standard deviation or medians with interquartile range, as appropriate. The Shapiro-Wilk test was used to assess the assumption of normality. Categorical data were compared using the $\chi^{2}$ test or Fisher exact test as appropriate. Mann-Whitney $\mathrm{U}$ tests was used to compare continuous variables. Pearson correlation with $\mathrm{R}$ square was used to analyze the correlation. Receiver operator characteristic (ROC) curves were used to analyze the ability of RRI to predict AKI. ROC curve analyses are reported as AUROC with $95 \%$ confidence interval (95\% CI). Optimal cut-off scores were determined using Youden's Index. Differences in repeated measurements in the two groups were analyzed using Friedman's rank analysis. Statistical analyses were performed using SPSS 25.0 statistical software (SPSS Inc., Chicago, IL). For each statistical test a 2-tailed test was performed and a $p$ value of 0.05 was considered statistically significant.

\subsection{Sample size}

Using the upper confidence interval for the population variance approach to the sample size calculation a pilot sample size between 20 and 40 correspond to standardized effect sizes of 0.4 and 0.7 (for $90 \%$ power based on a standard sample size calculation). According to this issue, 30 patients (15 for each group) were included in the study.

\section{Results}

\subsection{Population and renal blood flow evaluation}

We included in the study 30 patients with ARDS, of which 15 had laboratory-confirmed SARS-COV-2 ARDS. Clinical characteristics and blood gas analysis at ICU admission are shown in Table 1. The median driving pressure was 12 [10-15] $\mathrm{cm} \mathrm{H}_{2} \mathrm{O}$, resulting in a static compliance of 43 [40-52] $\mathrm{cm} \mathrm{H}_{2} \mathrm{O} / \mathrm{ml}$. Patients in the SARS-COV-2 ARDS group had lower $\mathrm{PaO}_{2} / \mathrm{FiO}_{2}$, higher $\mathrm{PaCO}_{2}$ and higher respiratory system compliance (Table 2).

The renal blood flow evaluation was performed after 1 [0-1] day from starting of MV. As shown in Table 1, compared with patients with classical ARDS, patients with SARS-COV-2 ARDS had higher RRI (0.71 [0.67-0.78] vs 0.64 [0.60-0.74], $p=0.04$ ) (Fig. 2). In patients with SARSCOV-2 ARDS, but not in patients with classical ARDS, there was a linear correlation between PEEP and RRI $\left(\mathrm{r}^{2}=0.31 ; p=0.03\right)$ (Fig. 3$)$. The RVF was not-continuous in $9 / 15$ patients $(71 \%)$ in SARS-COV-2 ARDS group and $5 / 15(33 \%)$ in not-CoV-2 $(p=0.27)$.

\subsection{Secondary outcomes}

AKI occurred in 8/15 of patients (53\%) in SARS-COV-2 ARDS and in 5/15 (33\%) in classical ARDS $(p=0.46)$. AKI was detected after 2 [1, 2] days (range 1-4) from renal blood flow evaluation. Four patients $(4 / 15,27 \%)$ in SARS-COV-2 ARDS group needed RRT versus one in the classical ARDS group $(1 / 15,6 \% ; p=0.33)$. Additional data regarding SARSCOV-2 ARDS patients are given in Table S1 and Fig. S1. In particular, SARS-COV-2 ARDS patients with AKI were more likely to experience a subsequent impairment in respiratory system compliance (Fig. S1). Taking into account the whole population, patients who developed AKI had higher RRI (0.77 [0.73-0.80] vs 0.66 [0.60-0.69]; $p=0.001)$ as well as higher percentage of impaired RVF (13/13 vs 1/17; $p<0.001)$. The RRI was associated with the subsequent occurrence of AKI (AUROC 0.938 [0.93-0.99]; p <0.001). The Youden index analysis showed that RRI $>0.71$ was the best cut-off value to predict AKI, with $90 \%$ sensitivity and $100 \%$ specificity. The RRI was also a predictor for RRT (AUROC $=0.896$ [0.73-0.98]; best cut-off 0.77 ; sensitivity $80 \%$ specificity $92 \%$ ).

\section{Discussion}

The main finding of our study is that the renal blood flow is more compromised in mechanically ventilated patients with SARS-COV-2 ARDS than in patients with classical ARDS. 
Table 1 Clinical and demographical characteristics of patients at ICU admission
Table 2 Renal blood flow evaluation and respiratory mechanics in patients with C-ARDS and ARDS

\begin{tabular}{|c|c|c|c|c|}
\hline Variables & $\begin{array}{l}\text { All patients } \\
n=30\end{array}$ & $\begin{array}{l}\text { SARS-CoV-2 ARDS } \\
n=15\end{array}$ & $\begin{array}{l}\text { ARDS } \\
\mathrm{n}=15\end{array}$ & $P$ value \\
\hline Age & $64[60-72]$ & 62 [55-69] & $67[62-74]$ & 0.89 \\
\hline $\operatorname{Sex}(\mathrm{F} / \mathrm{M})$ & $5 / 25$ & $2 / 13$ & $3 / 12$ & 0.99 \\
\hline SOFA score at ICU admission & $8[5-10]$ & $6[4-10]$ & $9[8-10]$ & 0.05 \\
\hline Need for vasopressor, n (\%) & $12(40)$ & $5(33)$ & $7(47)$ & 0.71 \\
\hline Epinephrine, n (\%) & $1(3)$ & - & \multirow[t]{2}{*}{$1(7)$} & \\
\hline \multicolumn{2}{|l|}{ Norepinephrine, $\mathrm{n}(\%)$} & $5(33)$ & & \\
\hline \multicolumn{5}{|l|}{ Comorbidities } \\
\hline Hypertension, n (\%) & $17(57)$ & $8(53)$ & $9(60)$ & 0.71 \\
\hline $\mathrm{CKD}, \mathrm{n}(\%)$ & $7(23)$ & $3(20)$ & $4(27)$ & 0.99 \\
\hline $\mathrm{BMI}>35\left(\mathrm{~kg} / \mathrm{m}^{2}\right), \mathrm{n}(\%)$ & $3(10)$ & $1(7)$ & $2(13)$ & 0.99 \\
\hline Diabetes, n (\%) & $6(20)$ & $3(20)$ & $3(20)$ & 0.99 \\
\hline \multicolumn{5}{|l|}{ Reasons for ICU admission } \\
\hline Septic shock & 4 & $4(27)$ & - & 0.09 \\
\hline ARDS & 26 & $11(73)$ & 15 & 0.09 \\
\hline \multicolumn{5}{|l|}{ Laboratory data at ICU admission } \\
\hline Hemoglobin (g/dL) & $11.0[9.8-13.6]$ & $10.9[9.6-12.4]$ & $12.8[9.9-13.6]$ & 0.49 \\
\hline Platelets $\left(10^{9} / \mathrm{L}\right)$ & 219 [179-302] & 263 [204-305] & $208[143-301]$ & 0.19 \\
\hline Serum creatinine $(\mathrm{mg} / \mathrm{L})$ & $1.0[0.7-2.5]$ & $0.8[0.7-1.2]$ & $2.5[0.7-3.6]$ & 0.11 \\
\hline
\end{tabular}

$C K D$ Chronic kidney disease, $B M I$ body mass index, $P E E P$ positive end-expiratory pressure, $\mathrm{PaCO}_{2}$ arterial carbon dioxide tension

\begin{tabular}{|c|c|c|c|}
\hline Variables & SARS-CoV-2 ARDS $n=15$ & $\begin{array}{l}\text { ARDS } \\
\mathrm{n}=15\end{array}$ & $P$ value \\
\hline \multicolumn{4}{|l|}{ Renal blood flow evaluation } \\
\hline Renal resistivity index & $0.71[0.67-0.78]$ & $0.64[0.60-0.74]$ & 0.04 \\
\hline \multicolumn{4}{|l|}{ Renal venous flow pattern } \\
\hline Continuous & $6(40)$ & $10(66)$ & 0.27 \\
\hline Biphasic & $4(27)$ & $3(20)$ & 0.99 \\
\hline Monophasic & $5(33)$ & $2(14)$ & 0.40 \\
\hline \multicolumn{4}{|l|}{ Respiratory mechanics } \\
\hline Tidal volume (mL) & $440[400-480]$ & $395[350-480]$ & 0.27 \\
\hline Respiratory rate & $18[18-22]$ & $18[16-20]$ & 0.14 \\
\hline Minute ventilation $(\mathrm{L} / \mathrm{m})$ & $7.9[7.2-9.0]$ & $7.4[6.0-8.6]$ & 0.10 \\
\hline Plateau pressure $\left(\mathrm{cm} \mathrm{H}_{2} \mathrm{O}\right)$ & $22[22-24]$ & $21[18-24]$ & 0.11 \\
\hline $\operatorname{PEEP}\left(\mathrm{cm} \mathrm{H}_{2} \mathrm{O}\right)$ & $14[12-14]$ & $10[10-12]$ & 0.004 \\
\hline Driving pressure $\left(\mathrm{cm} \mathrm{H}_{2} \mathrm{O}\right)$ & $10[8-10]$ & $9[8-12]$ & 0.90 \\
\hline Static compliance $\left(\mathrm{ml} / \mathrm{cm} \mathrm{H}_{2} \mathrm{O}\right)$ & $45[41-52]$ & $40[37-47]$ & 0.03 \\
\hline \multicolumn{4}{|l|}{ Hemodynamic parameters } \\
\hline Mean arterial pressure $(\mathrm{mmHg})$ & $75[70-80]$ & 82 [67-91] & 0.21 \\
\hline Heart rate & $90[86-104]$ & 89 [79-95] & 0.84 \\
\hline \multicolumn{4}{|l|}{ Blood gas analysis } \\
\hline $\mathrm{PaO}_{2} / \mathrm{FiO}_{2}(\mathrm{mmHg})$ & 118 [94-151] & 193 [148-209] & 0.001 \\
\hline $\mathrm{PaCO}_{2}(\mathrm{mmHg})$ & $57[48-64]$ & $46[36-52]$ & 0.02 \\
\hline Lactate $(\mathrm{mmol} / \mathrm{L})$ & $1.2[1.2-1.6]$ & $2.2[1.1-3.2]$ & 0.13 \\
\hline
\end{tabular}

SARS-CoV-2 ARDS Coronavirus-induced ARDS; PEEP positive end-expiratory pressure, $\mathrm{PaCO}_{2}$ arterial carbon dioxide tension 


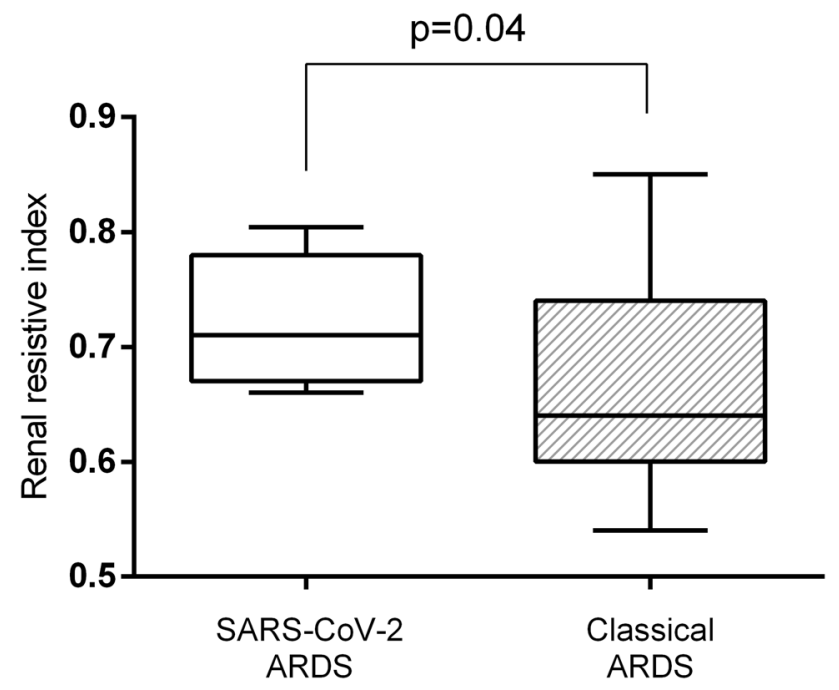

Fig. 2 Comparison of renal resistivity index or ARDS

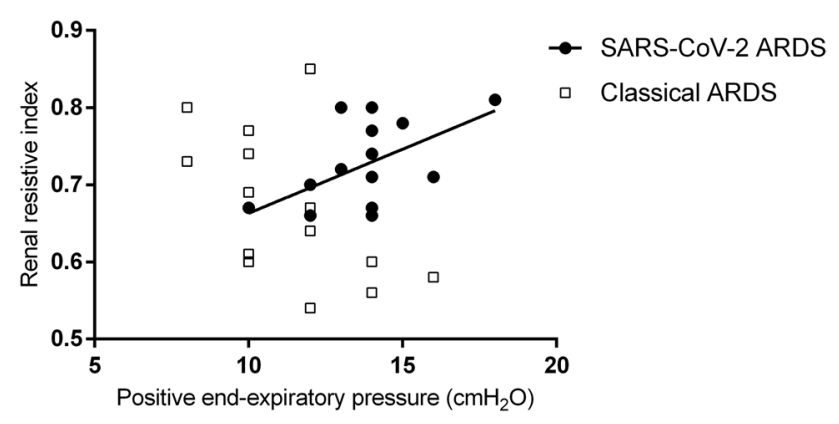

Fig. 3 Correlation between PEEP level and renal resistivity index in patients with SARS-CoV-2 ARDS or ARDS

The pathogenesis of renal dysfunction in patients with COVID 19 is multifactorial [2, 3, 19]. A recent observational study including 116 hospitalized patients shows that non ventilated patients with SARS-CoV-2 pneumonia seldom develop AKI [20]; conversely, the incidence of AKI was up to $23 \%$ in patients requiring respiratory support [1]. Despite the most severe disease form in ventilated patients could explain these findings, positive pressure ventilation could per se play a role [5-8]. Lung protective mechanical ventilation protocols for ARDS may result in relatively high PEEP levels, that may critically increase the pericardial pressure decreasing the venous return and causing glomerular congestion via the increase in kidney interstitial hydrostatic pressure [6,7], which increases arterial resistances [6, 7]. Our data confirm that SARS-CoV-2 induced ARDS is characterized by an atypically high respiratory system compliance $\left(\mathrm{C}_{\mathrm{RS}}\right)$, compared to the degree of arterial hypoxemia $[9,10,21,22]$ Since the hemodynamic effects of PEEP are enhanced when the $C_{R S}$ is relatively high [22-24], we speculate that the effect of PEEP on kidney perfusion could have been more pronounced in patients with SARS-CoV-2 ARDS than in those with classical ARDS. This hypothesis is supported by recent findings showing hemodynamics alteration given by "higher" PEEP levels in SARS-CoV-2 ARDS with static respiratory compliance higher than or equal to $50 \mathrm{~mL} / \mathrm{cm} \mathrm{H}_{2} \mathrm{O}$ [24]. Our finding of a linear relationship between RRI and PEEP in patients with SARS-CoV-2 ARDS and not in patients with ARDS (Fig. 3) and the fact that the RVF was not-continuous in $71 \%$ of our patients SARS-COV-2 ARDS seems to support this hypothesis. The RRI has recently gained importance as a marker of renal perfusion and to predict AKI [11-13, 25] and its severity [26]. On the other hand, the non-continuous RVF pattern suggests glomerular congestion, which may be an additional cause of renal blood flow impairment [11]. High RRI is associated with need for vasopressors, hypotension and lactate levels [12], whereas non-continuous RVF have been described in the context of increased pulmonary wedge pressure [11]. Even if the RRI difference between SARS-CoV-2 ARDS and classical ARDS could seems numerically low (0.71 [0.67-0.78] vs 0.64 [0.60-0.74]), it reflects a clinically relevant change. Indeed, as showed in previous studies, RRI value over 0.70 is a threshold useful to discern between a normal or a pathological renal blood flow [12, 27]. In particular, RRI $>0.70$ was associated with persistent AKI [12] and worse renal prognosis [27] when compared to RRI values between 0.65 and 0.70 .

Our study has some limitations. First, due to the lack of clinical study in this field, we were unable to perform an accurate power analysis and the small sample size could limit the interpretation of our results and does not account for covariate adjustment. Second, our study was not designed to separate between the different mechanism that could explain the impairment of renal blood flow. Nonetheless, the correlation between PEEP levels and RRI seems to suggest a possible role of mechanical ventilation in the RRI impairment. Finally, we cannot exclude that the water overload in SARS-COV-2 ARDS could have contribute to the described renal congestion and therefore renal impairment. Nonetheless, hemodynamic monitoring was not systematically available in our patients and therefore it would be impossible to correctly analyses this issue with our data.

\section{Conclusions}

In conclusion, we showed that during lung-protective mechanical ventilation, the renal blood flow is more impaired in patients with SARS-CoV-2 ARDS than in patients with classical ARDS. Our findings suggest to carefully assess renal blood flow and even subtle signs of AKI in patients with SARS-CoV-2 ARDS requiring mechanical 
ventilation. Further studies are needed to assess the specific role of mechanical ventilation in the pathogenesis of the SARS-CoV-2 ARDS kidney perfusion impairment and, eventually, if different approaches to PEEP setting could better preserve renal perfusion.

Acknowledgements The authors would like to thank all the nurses and caregivers for their active involvement in the management of patients during this study.

Authors' contributions FA, VCA and SS was involved in the conception and the design of the study, analyzed the data and wrote the paper. FA and ME collected the data. FA performed the statistical work. MD, GS, FM and LG contributed to analysis of the data and critical revision of the manuscript for important intellectual content. All authors reviewed the manuscript and agreed with the final version.

Fundings This study was financially supported by the University of Ferrara, Ferrara, Italy.

\section{Compliance with ethical standard}

Conflict of interest The authors declare that they have no competing interests.

Informed consent Prospective, observational pilot study performed in a COVID-19 Intensive Care Unit (ICU) and a mixed medical-surgical ICU at University Hospital of Ferrara, Italy. The study was approved by the ethic committee (approval number 339/2020). We included consecutive patients with SARS-COV-2 ARDS or ARDS undergoing mechanical ventilation. Exclusion criteria were: diagnosis of AKI before ICU admission, unsatisfactory ultrasound visualization, arrhythmia, renal replacement therapy and denied consent. All patients included in the SARS-COV-2 ARDS group had laboratory-confirmed COVID-19.

Ethical standards The study was approved by the ethic committee (approval number 339/2020).

\section{References}

1. Yang X, Yu Y, Xu J, Shu H, Xia J, Liu H, et al. Clinical course and outcomes of critically ill patients with SARS-CoV-2 pneumonia in Wuhan, China: a single-centered, retrospective, observational study. Lancet Respir Med. 2020;8(5):475-81. E-pub ahead of printing

2. Pei G, Zhang Z, Peng J, Liu L, Zhang C, Yu C, et al. Renal involvement and early prognosis in patients with COVID-19 pneumonia. J Am Soc Nephrol. 2020;31(6):1157-65. E-pub ahead of printing

3. Cheng Y, Luo R, Wang K, Zhang M, Wang Z, Dong L, et al. Kidney disease is associated with in-hospital death of patients with COVID-19. Kidney Int. 2020;5:829-38.

4. Poston JT, Patel BK, Davis AM. Management of critically Ill adults with COVID-19. JAMA. 2020; E-pub ahead of printing

5. Vieillard-Baron A, Loubieres Y, Schmitt JM, Page B, Dubourg $\mathrm{O}$, Jardin F. Cyclic changes in right ventricular output impedance during mechanical ventilation. J Appl Physiol. 1999;87:1644-50.

6. Joannidis M, Forni LG, Klein SJ, Honore PM, Kashani K, Ostermann M, et al. Lung-kidney interactions in critically ill patients: consensus report of the Acute Disease Quality Initiative (ADQI) 21 Workgroup. Intensive Care Med. 2020;46(4):654-72.
7. Panitchote A, Mehkri O, Hastings A, Hanane T, Demirjian S, Torbic $\mathrm{H}$, et al. Factors associated with acute kidney injury in acute respiratory distress syndrome. Ann Intensive Care. 2019;9(1):74.

8. Gurkan OU, O’Donnell C, Brower R, Ruckdeschel E, Becker PM. Differential effects of mechanical ventilatory strategy on lung injury and systemic organ inflammation in mice. Am J Physiol Lung Cell Mol Physiol. 2005;285:L710-8.

9. Grasselli G, Zangrillo A, Zanella A, Antonelli M, Cabrini L, Castelli A, et al. Baseline characteristics and outcomes of 1591 patients infected with SARS-CoV-2 admitted to ICUs of the Lombardy Region Italy. JAMA. 2020;323(16):1574-81.

10. Gattinoni L, Chiumello D, Rossi S. COVID-19 pneumonia: ARDS or not? Crit Care. 2020;24:154.

11. Husain-Syed F, Birk HW, Ronco C, Schörmann T, Tello K, Richter MJ. Doppler-derived renal venous stasis index in the prognosis of right heart failure. J Am Heart Assoc. 2019;8(21):e013584.

12. Oliveira RAG, Mendes PV, Park M, Taniguchi LU. Factors associated with renal Doppler resistive index in critically ill patients: a prospective cohort study. Ann Intensive Care. 2019;9(1):23.

13. Dewitte A, Coquin J, Meyssignac B, Joannès-Boyau O, Fleureau $\mathrm{C}$, Roze $\mathrm{H}$, et al. Doppler resistive index to reflect regulation of renal vascular tone during sepsis and acute kidney injury. Crit Care. 2012;16(5):R165.

14. Pereira Romano ML, Maia IS, Laranjeira LN, Damiani LP, Paisani DM, Borges MC. Driving pressure-limited strategy for patients with Acute Respiratory Distress Syndrome (ARDS): a pilot randomized clinical trial. Ann Am Thorac Soc. 2020;17(5):596-604. E-pub ahead of printing

15. Sahetya SK, Hager DN, Stephens RS, Needham DM, Brower RG. PEEP titration to minimize driving pressure in subjects with ARDS: a prospective physiological study. Respir Care. 2020;65(5):583-9. https://doi.org/10.4187/respcare.07102.

16. Hess DR. Respiratory mechanics in mechanically ventilated patients. Respir Care. 2014;59(11):1773-94. https://doi. org/10.4187/respcare.03410.

17. Khwaja A. KDIGO clinical practice guidelines for acute kidney injury. Nephron Clin Pract. 2012;120:c179-84.

18. Bagshaw SM, Cruz DN, Gibney RT, Ronco C. A proposed algorithm for initiation of renal replacement therapy in adult critically ill patients. Crit Care. 2009;13:317.

19. Su H, Yang M, Wan C, Yi LX, Tang F, Zhu HY, et al. Renal histopathological analysis of 26 postmortem findings of patients with COVID-19 in China. Kidney Int. 2020;98(1):219-27. E-pub ahead of printing

20. Wang L, Li X, Chen H, Yan S, Li D, Li Y. Coronavirus disease 19 infection does not result in acute kidney injury: an analysis of 116 hospitalized patients from Wuhan, China. Am J Nephrol. 2020;51(5):1-6.

21. Marini JJ, Gattinoni L. Management of COVID-19 respiratory distress. JAMA. 2020;323(22):2329. E-pub ahead of printing

22. Gattinoni L, Chiumello D, Caironi P, Busana M, Romitti F, Brazzi L, et al. COVID-19 pneumonia: different respiratory treatments for different phenotypes? Intensive Care Med. 2020;46(6):1099102. E-pub ahead of printing

23. Chen X, Wang X, Honore PM, Spapen HD, Liu D. Renal failure in critically ill patients, beware of applying (central venous) pressure on the kidney. Ann Intensive Care. 2018;8(1):91.

24. Grasso S, Mirabella L, Murgolo F, Di Mussi R, Pisani L, Dalfino $\mathrm{L}$, et al. Effects of positive end-expiratory pressure in "High Compliance" severe acute respiratory syndrome coronavirus 2 acute respiratory distress syndrome. Crit Care Med. 2020;48(12):e1332-6. https://doi.org/10.1097/CCM.0000000000 004640. Epub ahead of print

25. Garnier F, Daubin D, Larcher R, Bargnoux AS, Platon L, Brunot V. Reversibility of acute kidney injury in medical 
ICU patients: predictability performance of urinary tissue inhibitor of metalloproteinase- $2 \times$ insulin-like growth factorbinding protein 7 and renal resistive index. Crit Care Med. 2020;4:e277-84.

26. Haitsma Mulier JLG, Rozemeijer S, Röttgering JG, Spoelstra-de Man AME, Elbers PWG, Tuinman PR, et al. Renal resistive index as an early predictor and discriminator of acute kidney injury in critically ill patients: a prospective observational cohort study. PLoS One. 2018;13(6):e0197967.

27. Sugiura T, Wada A. Resistive index predicts renal prognosis in chronic kidney disease. Nephrol Dial Transplant. 2009;24(9):2780-5.

Publisher's Note Springer Nature remains neutral with regard to jurisdictional claims in published maps and institutional affiliations 